\title{
Psicanálise e Cuidados Paliativos: do sem-sentido à invenção
}

Sílvio Memento MACHADO*

\begin{abstract}
* Psicólogo. Psicanalista. Mestre em Educação. Professor da Universidade José do Rosário Vellano - UNIFENAS e da Faculdade de Direito de Varginha - FADIVA. silvio.memento67@gmail.com

"Assim que nasce, o homem já tem idade suficiente para morrer". Heidegger
\end{abstract}

Recebido em: 05/07/2015 - Aprovado em: 05/11/2015 - Disponibilizado em: 18/12//2015

Resumo:O presente artigo traz uma discussão sobre o que pode um psicanalista diante de um paciente terminal emcuidadospaliativos. Trata-se de um trabalho baseado na experiência do autor e referenciado na teoria psicanalítica. Conclui-se que diante do sem-sentido da morte, o que resta é a chance de se inventar saídaspossíveis, o que cada sujeito faz de um modo singular.

Palavras-chave: Paciente Terminal. Cuidados Paliativos. Morte. Psicanálise. Invenção.

Abstract:Thisarticlebringsusaboutwhat a psychoanalystcan do in the face of a terminal patient in palliativecares. That's a workbased in theauthorexperienceandreferable in psychoanalitictheory. Wecanconclude in face tothewithoutsensedeath, thechance ofinventionofpossibleexitsthatwhatremains, whatanyonecan do in a singular way.

Key words: Terminal Patient. PalliativeCares. Death. Psychoanalysis. Invention.

\section{Introdução}

Ao ser convidado para participar de umsimpósio sobre Cuidados Paliativos, na condição de palestrante, o autor deste artigo se perguntou sobre o que um psicanalista teria a dizer a respeito do tratamento de uma pessoa cuja morte, a princípio, já tem uma data marcada. Normalmente, trata-se alguém que almeja operar mudanças na sua vida num tempo que se espera seja longo, ou pelo menos o suficiente para isto. Aliás, talvez com poucas exceções, vive-se como se a morte, como fim, não fosse um fato ou que existisse apenas num tempo muito distante, ao final de uma vida longa e feliz. Por mais que se lidecom perdas de pessoas próximas, com a decadência da vitalidade do corpo por doenças ou pelo processo natural do envelhecimento, a morte é sempre a do outro, nunca a própria. Assim, optou-se por falar sobre a relação que se tem com a morte.

\section{A morte, a psicanálise e os cuidados paliativos}

Do ponto de vista social, a morte é uma "sem lugar". Relegada à UTI dos hospitais, na maioria das vezes, a morte simplesmente não combina com uma sociedade que prega, a todo instante, que o grande barato é curtir, é não sofrer. Nem 
sempre foi assim. Historicamente, a morte, embora sempre vivida com dor e sofrimento, já fez parte do cotidiano da vida das pessoas,numa época em que os ideias de juventude eterna e de prazer permanente não eram soberanos.

Quando não pensar sobre a morte torna-se impossível, cria-se explicações transcendentes: aponta-se para uma outra vida, numa dimensão diferente daquela em que se viveaqui, ou encontra-se um suposto propósito para a vida retratado nos termos: missão, destino, carma, sina, vontade divina e tantos outros. Enfim, de diferentes formas, o que se quer é dar um sentido à vida diante da angústia que a morte, como fim, mobiliza.

A psicanálise, como campo de conhecimento e de intervenção sobre o sofrimento psíquico, não se confunde com nenhuma perspectiva filosófica ou religiosa sobre a vida. Portanto, ela não compartilha com uma visão que remete o homem a uma transcendência. Isto não significa que ela seja contrária a que as pessoas busquem explicações religiosas sobre a vida e a morte. Isto é sempre algo muito particular e a psicanálise não pretende substituir nenhuma dessas convicções. Nada mais avesso à psicanálise do que a pretensão de se valer para todos, ser universalizante.

Os psicanalistas, simplesmente não trabalhamcom a noção de sentido da vida como algo já definido previamente na histórica pessoal, ou como aquilo a que um dia vai se chegardepois da morte. Por mais estranho ou mesmo espantoso que isto possa parecer a alguns, ou a vários, à luz da psicanálise a vida não tem nenhum sentido, o que não significa que ela não tenha valor,a não seraquele quese constrói à medida em que se vive.

Todavia, ao contrário do que se possa pensara princípio, esta não é uma visão pessimista da vida; é uma forma de encarar a existência numa dimensão mais real e menos idealizada, colocando o sujeito humano como responsável pelo que lhe acontece, sem que nada possa servir de desculpas para a acomodação, para a "desresponsabilização"pela própria vida.Assim, a psicanálise está na via oposta à do pagodeiro que canta: "deixa a vida me levar, vida leva eu".

Essa posição de responsável pela própria vida, no entanto, não significa que se está no comando de tudo o que acontece. Para serfiel à própria psicanálise, tem-se que levar em conta as determinações inconscientes que se expressam, sem o controle da consciência, através dossonhos, dos atos falhos (esquecimentos, trocas de nomes, etc), de atitudes na vida (as repetições) e também dossintomas (a forma com que se adoece). Igualmente, tem-se que considerar os imprevistos, aquilo que emerge como surpresa nocotidiano: um acidente, uma doença... Certamente, não se escolhetudo. Mas mesmo diante das fatalidades com as 
quais o ser humano se depara, ele é responsável pela forma como respondea essas situações (FORBES, 2012).

Dito isto, como lidar com aquele cuja morte já se avista no horizonte? Freud (1905/1977) contraindicava a análise para idosos dentre outras razões porque eles teriam pouco tempo de vida para fazer as mudanças que o próprio tratamento poderiasuscitar. Atualmente, em função, inclusive, do novo lugar que o idoso ocupa nasociedade, não se trabalhamais com essa restrição de Freud.

Acredita-se que é possível se fazer um paralelo entre o idoso, que vê seus dias contados, e o paciente que, embora em qualquer idade, não vê perspectivas de tempo de vida pela frente. Cabe destacar, no entanto, que quanto mais cedo a morte chega, mais ela surpreende e mais difícil é a sua aceitação, haja vista a frase tantas vezes repetida: "Morreu tão jovem, tinha tanta vida pela frente". Se não se recuamais diante do idoso por que o faria diante de um paciente terminal?

Então, para além dos cuidados paliativos, tão importantes para que alguém tenha uma vida (ainda que breve) e uma morte dignas, que cuidados do ponto de vista subjetivo poderia ser ofertado a um paciente terminal? Há trabalhos muito interessantes realizados porpsicanalistas junto a pacientes, familiares e profissionais que lidam com essa clientela. Destaca-se, também, o importante papel desempenhado pelos religiosos que, frequentemente, são aqueles na comunidade convocados a estar presentes nesses momentos e que, embora negando a morte como fim - pelo contrário, afirmando ser a morte apenas uma passagem - historicamente não se furtam a esse encontro.

Kübler-Ross (1988), a partir da sua prática com pacientes terminais, trouxe uma valiosa contribuição ao formular os estágios pelos quais esses pacientes passam, desde a negação, passando pela raiva, pela barganha, pela depressão, até a almejada aceitação da morte. Não se pretende deter aqui nessa teorização por não ser o objetivo deste trabalho e também por estarem já bastante difundidas as ideias dessa autora.

A psicanálise, como já se disse neste artigo, não nega a morte; ao invés disto, a afirma. Ao se fazer uma pequena digressão teórica, constata-se que Freud (1920/1976), nos anos vinte do século passado, formulou um dos seus conceitos mais enigmáticos: a pulsão de morte. Ele chegou a esse conceito através dos fenômenos clínicos relacionados à compulsão à repetição. Ele se perguntava sobre o que fazcom que alguém se coloque repetidamente na vida em situações dolorosasdas quais a própria pessoa chega ao consultório se queixando. $\mathrm{O}$ que Freud descobriu, a partir disto,foi a existência nofuncionamento psíquico de uma tendência, de uma força, que objetiva, em última instância, levar o organismo a um estado em que não haja mais nenhuma tensão no 
aparelho psíquico, ou seja, à morte. A pulsão de vida, por sua vez, é o queleva a fazer laços, vínculos, a investir na vida para que a morte se dê de forma natural e não precipitadamente. Portanto, a pulsão de vida não é o contrário da pulsão de morte, ela está a serviço desta última. Ainda, segundo Freud, pulsão de vida e pulsão de morte se entrelaçam durante toda a existência.

De alguma forma, e muitos profissionais podem atestá-lo, lidar com a morte do outro, por maiores que sejam asdefesas pessoais, é também se perguntar sobre aprópria vida e como se está nela empenhado, como dela se responsabiliza.

Sabe-se que a prática com pacientes terminais, mesmo a partir da psicanálise, comporta especificidades. De qualquer forma, não existe uma psicanálise aplicada a determinadas doenças ou faixas etárias. Os instrumentos dos quais o psicanalista se valee o sujeito a quem se destina o tratamento são os mesmos. Convoca-se esse sujeito a que fale e, em contrapartida, se ofereceaescuta. Mas se poderiaperguntar: "não é o mesmo que uma outra pessoa, um religioso ou um outro profissional fazem? Afinal eles também escutam." Não há dúvidas de que qualquer forma de escuta pode ser benéfica,terapêutica. Todavia, o que a psicanálise propõe e que marca a sua especificidade é o acolhimento da fala (ou até da recusa dela) na sua mais radical singularidade. Ou seja, um psicanalista não visa a dar nenhum sentido antecipado à fala do seu cliente, também não moraliza comportamentos, não aconselha quanto ao que fazer, não se coloca, enfim, como aquele que de antemão sabe o que é melhor para o outro. O que ele faz então? Oferece a sua escuta com a finalidade de que quem fala também se escute (coisa que pode ser muito estranha, mas igualmente reveladora). Quando se fala, num contexto de análise, nunca se diz exatamente o que se quer conscientemente dizer; a palavra ganha autonomia em relação ao eu e expressa aquilo que surpreende a consciência. Não é raro, após ouvir o que se disse, alguém comentar: "nunca tinha pensado nisso" ou "isso nunca me ocorreu antes". O analista está ali para sublinhar, destacar isto, para não deixar que essa fala reveladora (uma vez que comporta algo da verdade inconsciente do sujeito) passe despercebida, para não permitir que ela seja recoberta por outra (LACAN, 1986).

Nesse percurso, o sujeito pode se apropriar, ainda que parcialmente, daquilo que do inconsciente o causa; um saber vai se construindo a partir do não-saber enigmático do sintoma - "não sei o que está acontecendo comigo" - qualquer que ele seja. Destaca-se que esse saber não é o saber que o analisa possa ter sobre a psicanálise; é um saber de si produzido pelo próprio sujeito. Dizer a alguém sobre as possíveis causas do seu sintoma, à luz da teoria, nada muda no sintoma propriamente; ao contrário, pode até fortalecê-lo. Desse saber que se revela, o 
sujeito extrai consequências que podem implicar em remanejamentos significativos na sua vida. Em linhas gerais, uma análise transcorre assim.

Quanto ao paciente terminal, quando este se dispõe a se questionar nesse momento, mesmo que ele não faça uma análise, no sentido mais convencional do termo, o fato de ter sido tocado por essa dimensão reveladora da palavra, possibilitada pela escuta de um analista, talvez contribua para que ele possa inventar algum sentido para o que lhe ocorre. Destaca-se "inventar", pois não se trata aqui de aderir a um sentido já construído, dado $a$ priori.

Não é uma tarefa fácil, para nenhum dos dois lados, pois implica bastante trabalho, lidar com a angústia e com uma certa dose de solidão. Sem dúvidas, é menos trabalhoso aderir a uma rede de sentidos já construída e sentir-se pertencente a um grupo. No entanto, se assim funciona para muitos, sempre haverá um para quem as respostas prontas, embora apaziguadoras, não o contemplam como sujeito da sua própria vida e, porque não dizer, no caso do paciente terminal, sujeito da sua própria morte. Para este, a psicanálise pode fazer alguma diferença.

\section{Considerações finais}

Por conta do que se expôs, considerase relevante citar as palavras de Kübler-
Rosscom as quais ela conclui o seu clássico livro:

Aqueles que tiveram a força $\mathrm{e} o$ amor para ficar ao lado de um paciente moribundo com osilêncio que vai além das palavras saberão que tal momento não é assustador nem doloroso, mas um cessar em paz do funcionamento do corpo.Observar a morte em paz de um ser humano faz-nos lembrar uma estrela cadente. É uma entre milhões de luzes do céu imenso,que cintila ainda por um breve momento para desaparecer para sempre na noite sem fim. Ser terapeuta de um paciente que agoniza é conscientizar-se da singularidade de cada indivíduo neste oceano imenso da humanidade. É uma tomada de consciência da nossa finitude, do nosso limitado tempo de vida. Nesse curto tempo de vida,muitos dentre nós criam e vivem uma biografia única e nós mesmos tecemos a trama da história humana(KÜBLER-ROSS, 1988, p. 282).

Finaliza-se destacando a seguinte expressão utilizada por essa autora: “o silêncio que vai além das palavras". E é isto mesmo: a morte, por mais que diversos discursos possam dela falar - religião, filosofia, medicina e a própria psicanálise remete sempre ao limite, não só da palavra,mas também do sentido. Diante desse vazio - de palavras, de sentido - cada um, na sua singularidade, é convocado a se posicionar de uma maneira criativa transfigurando, assim, o horror em investimento e amor à vida. 


\section{REFERÊNCIAS:}

FORBES, J. Inconsciente e

responsabilidade: psicanálise do século

XXI. Barueri (SP): Manole, 2012.

FREUD, S. Sobre a psicoterapia. In: Edição

standard brasileira das obras psicológicas completas de Sigmund Freud, vol. 7. Rio de Janeiro: Imago, 1977. (Trabalho original publicado em 1905).

FREUD, S. Além do princípio do prazer. In:

Edição standard brasileira das obras psicológicas completas de Sigmund Freud, vol. 18. Rio de Janeiro: Imago, 1976.

(Trabalho original publicado em 1920).

KÜBLER-ROSS, E. Sobre a morte e o morrer. São Paulo: Martins Fontes, 1998.

LACAN, J. O seminário - livro 1: Os escritos técnicos de Freud. Rio de Janeiro: Jorge Zahar Ed., 1986. 